\title{
Ensuring Rights and Full Participation Regardless of Social and Economic Position
}

In the early 1950s, just a few years after India gained independence, Banamali Das was earning his living making shoes in Suri, a town in West Bengal. One day, he visited the local barbershop for a haircut. Yet the barber, Pakhu Bhandari, refused to serve him—or any other member of his caste. ${ }^{1}$

In January 1951, Das filed a complaint against Bhandari, arguing that Bhandari's refusal to cut his hair violated the West Bengal Hindu Social Disabilities Removal Act of 1949. Under the act, no Hindu — a broadly defined designation ${ }^{2}$ - could be "denied any service whatsoever" on the ground that he "belongs to a particular caste or class ... by a Hindu who habitually renders such service in the course of his profession." Das belonged to a lower caste largely comprising cobblers and leatherworkers, and according to his complaint, Bhandari had categorically declined their business. In his defense, Bhandari claimed the act infringed on his constitutional right to freely practice his profession. Furthermore, he alleged that the act violated his own constitutional right to equality.

When the case reached the High Court of Calcutta, however, the judges quickly dispensed with these arguments. First, as the Court noted, rather than prevent Bhandari from practicing his profession, the act in fact "enlarge[d] the scope of his 
services" by compelling him to "serve all alike."3 By contrast, the Court explained, if the act had prohibited barbers from providing services to those from lowercaste backgrounds, it clearly would have infringed upon their work rights. Further, restrictions on the right to practice a profession could nevertheless be constitutional if they were reasonable and served a public purpose. ${ }^{4}$

Turning to Bhandari's claim that the new law violated his right to equality, the Court found that the act in fact had the opposite effect; the equality provision of India's constitution "is directed against discrimination and what the impugned Act wishes to abolish is discrimination."5 Furthermore, the Court clarified that "the general scheme of the Act is to protect the lower castes against being discriminated against by the higher castes and to make all castes or classes of Hindus equal in the social, civic and religious fields." ${ }^{\prime \prime}$ As a result, rather than infringe upon it, the act would only further the goals of the new constitution, which specifically prohibited caste discrimination. Moreover, the ruling highlighted the importance of ensuring that laws regulating the provision of private services affirm constitutional protections of equality - an issue that continues to be relevant in 2019, especially in the context of LGBT+ discrimination.

The Banamali Das case illustrates one way in which discrimination on the basis of socioeconomic status takes place-and how constitutions can address it. Das experienced explicit discrimination based on his social status, which was clearly prohibited by both the national constitution and more targeted legislation. More recent cases from India have made clear that, in addition to the explicit bias on display in Banamali Das, financial barriers to key resources like health and education are also rightfully understood as unconstitutional discrimination on the basis of socioeconomic status. For example, in a 1992 case, the Supreme Court held that the exorbitant fees required to attend a private medical school made "the availability of education beyond the reach of the poor," therefore violating the constitution's equality provision. ${ }^{7}$

Global human rights agreements prohibit discrimination on the basis of class. The Universal Declaration of Human Rights (UDHR), adopted by the U.N. in 1948, guarantees all rights and freedoms without distinction on the basis of "social origin, property, birth or other status," as do the International Covenant on Economic, Social and Cultural Rights (ICESCR), the International Covenant on Civil and Political Rights (ICCPR), and the Convention on the Rights of the Child (CRC), among other treaties. These international agreements also make clear that the rights to health services and education should be equally accessible to all. More recently, through the Sustainable Development Goals (SDGs), all 193 U.N. countries agreed to take steps between 2015 and 2030 to "end poverty in all its forms everywhere," reduce inequality, end hunger, ensure inclusive education, and address other fundamental barriers to the well-being of all people, regardless of socioeconomic status and other factors. ${ }^{9}$ 
The 1950 Indian Constitution, which abolished "untouchability" and prohibited caste discrimination, was a sharp repudiation of the country's widely known caste system and a global milestone for equal rights regardless of socioeconomic status. But globally, how many countries have embedded these commitments in their constitutions and explicitly prohibit discrimination on grounds like income, wealth, social origin, or property? And how do broader aspects of countries' legal systems, including the accessibility of courts, shape rights for people who are economically marginalized?

\section{SOCIOECONOMIC STATUS AND \\ DISCRIMINATORY BARRIERS}

The concept of socioeconomic status (SES) or social position in constitutions and elsewhere is operationalized in a range of ways, including with respect to inherited status, income and wealth, educational attainment, and occupation. ${ }^{10}$ Together, these and other factors shape SES, which is generally understood as an individual's social and economic position relative to others.

Discrimination on the basis of SES manifests in a variety of ways. While explicit class or caste discrimination remains critical to address, subtler forms of SES discrimination also markedly impact opportunities and inclusion, and barriers to the exercise of other rights linked to SES present profound challenges for equity. A brief survey of some of the research and history in these areas offers important context for the potential of constitutional approaches.

\section{Direct Discrimination: Class, Caste, and Property}

Globally, SES discrimination, and particularly discrimination against the poor, has a long history in the law. Under feudalism, which structured European societies throughout the Middle Ages, social status and rights hinged on land ownership. Beginning in the fourteenth century and continuing for nearly 500 years, "poor laws" governed the lives of people in poverty in Elizabethan England, prohibiting alms-giving to the "able-bodied" poor, threatening servants with imprisonment if they quit a job, and creating "poorhouses" to segregate those in poverty from the general population, where they often lived in squalid, unsafe conditions. ${ }^{11}$ In other countries, rigid SES-based social hierarchies governed access to jobs and education for centuries. ${ }^{12}$

SES continued to play a definitional role in the first constitutions, some of which made property ownership a prerequisite for full citizenship. Under the 1791 French Constitution, for instance, only "active citizens"- which did not include paid servants-could serve as electors in the National Legislative Assembly, and only if they lived or worked on a property that met a minimum value requirement specified in the constitutional text. ${ }^{13}$ Likewise, New York's first constitution, adopted in 1777 , restricted the right to vote to male citizens who possessed a "freehold of 
the value of twenty pounds, within the said county, or have rented a tenement therein of the yearly value of forty shilling." ${ }^{14}$ The U.S. Constitution, adopted 12 years later, left the door open to state-level property restrictions on the right to vote that would persist through the late nineteenth century.

Today, in some communities, landownership continues to dictate who participates in local decision-making processes-a barrier to entry that disproportionately impacts women, partly because of discriminatory inheritance laws. ${ }^{15}$ Moreover, more formal class and caste systems, despite having been legally abandoned, continue to structure societies and interpersonal relationships in parts of the world because of their historical entrenchment. Against this backdrop, protections against explicit SES discrimination remain relevant and necessary.

\section{Class Discrimination by Proxy: Names, Neighborhoods, and Accents}

Although SES discrimination is generally less explicit or codified than in centuries past, poverty remains stigmatized in many countries, and SES discrimination persists in more invidious ways. Often, this discrimination is based on class signifiers rather than direct assessments of income, property, education, or profession.

For example, in modern-day India, studies have found that employers continue to discriminate on the basis of caste not by posting caste-specific job advertisements but by examining applicants' names. In 2006, researchers in Chennai submitted over a thousand fictitious resumes for entry-level jobs. While every resume reflected very similar levels of experience and education, there was one critical difference: the researchers used names widely affiliated with higher castes for half the applications, and distinctively low-caste names for the other half. The results clearly indicated that caste still matters: applicants with low-caste names had to send out $20 \%$ more resumes just to receive callbacks. ${ }^{16}$

Studies from other parts of the world have documented a similar phenomenon, while further illustrating how SES discrimination and racial/ethnic discrimination are often deeply intertwined. A U.S. field experiment that involved submitting 5,000 fictitious resumes in response to 1,300 job ads found that applicants with "white" names received about 50\% more callbacks than those with names perceived as more commonly African American. Yet across the applicant pool, the address listed on the resume-a proxy for the applicant's neighborhood and social class-had an independent effect, with those living in wealthier areas receiving more favorable treatment. ${ }^{17}$

Aspects of personal appearance or speech suggesting lower SES have also been identified as bases of discrimination. Research has shown that inadequate access to affordable dental care is the primary factor driving inequalities in oral health between the rich and poor. ${ }^{18}$ Surveys, however, find that many people attribute "bad teeth" to personal choices and neglect, thereby justifying discriminatory attitudes on the basis of poor dental appearance. ${ }^{19}$ Likewise, in many countries, accents and language usage have become class signifiers. ${ }^{20}$ In Britain, over a quarter of people 
report facing discrimination because of their accents, and surveys of employers have confirmed the accuracy of their perceptions. ${ }^{21}$

Mounting research shows that experiences of SES discrimination, like racial discrimination, negatively affect physical and mental health. ${ }^{22}$ A study of 252 American adolescents, for example, found that perceived SES discrimination accounted for $13 \%$ of the negative impacts of poverty on aspects of health like blood pressure and cortisol levels. ${ }^{23}$ Moreover, SES discrimination interacts with other forms of discrimination and is worse when combined with other bases of discrimination. ${ }^{24}$ The persistence of SES discrimination, alongside the significant body of evidence that experiences of discrimination have profound consequences for health ${ }^{25}$ as well as education, work, and income, underscores the urgency of action.

\section{Economic Barriers to Health and Education}

Beyond SES discrimination, income barriers affect the ability to realize the fundamental rights to health ${ }^{26}$ and education, ${ }^{27}$ which in turn affects access to jobs and civic and political participation. Across low- and middle-income countries, the imposition of fees to access public healthcare has been found to widen socioeconomic disparities in access to health services, and increase the risk of preventable diseases and deaths. ${ }^{28}$ Likewise, in high-income countries without universal healthcare, such as the United States, the costs of medical treatments and prescriptions have been shown to deter low-income individuals from accessing needed care, while driving others to bankruptcy. ${ }^{29}$

In education, tuition fees for primary and secondary school have been found to keep poor students and girls out of the classroom-while abolishing fees has the opposite effect. ${ }^{30}$ Likewise, the high costs of higher education often make it more challenging for lower-SES students to get their degrees, erecting insurmountable barriers to entry for some while driving others to balance multiple jobs with their coursework to make ends meet. Finally, while unequal educational opportunities can translate into unequal work opportunities, SES discrimination can also directly affect success in the labor market. For example, a study of graduates from a large, highly ranked public university in Chile found that those from lower-SES backgrounds went on to earn $35 \%$ less than their higher-SES peers, controlling for academic performance, second-language proficiency, postgraduate studies, geographic origin, and other factors. ${ }^{31}$

Addressing disadvantage linked to SES consequently requires addressing all three elements: direct SES discrimination, discrimination on the basis of other characteristics commonly associated with lower SES, and policies and practices that indirectly impede full participation in society and exercise of other rights by people with fewer economic resources. To what extent can constitutions address these barriers, and how have existing constitutional approaches to SES discrimination made a difference? 


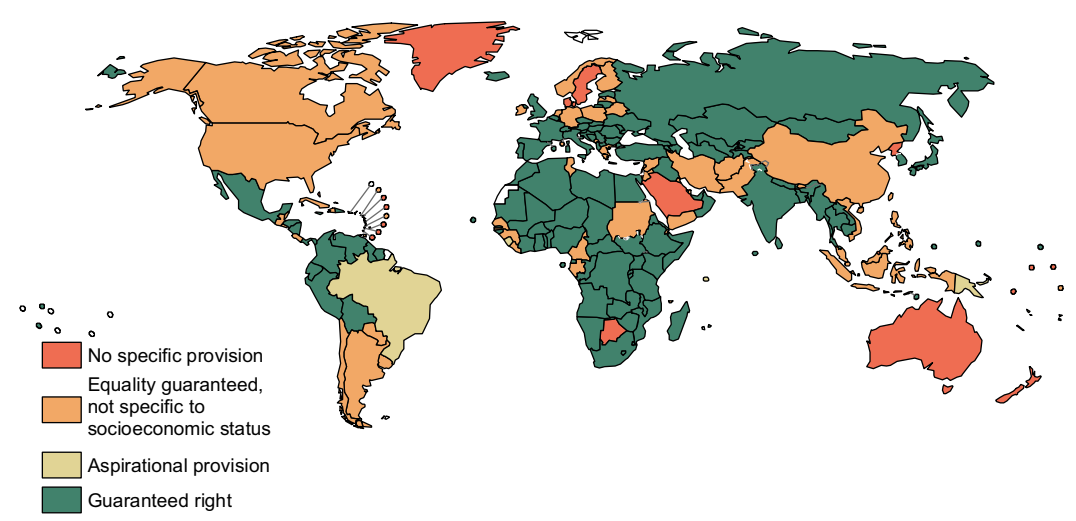

MAP 24. Does the constitution explicitly guarantee equality or nondiscrimination across socioeconomic status?

\section{CONSTITUTIONAL APPROACHES AND IMPACTS}

Current constitutions shape the impact of SES on the full exercise of rights in several key ways. First, and most directly, some constitutions explicitly prohibit SES discrimination, which can provide a tool for challenging identifiable forms of bias and dismantling the vestiges of discriminatory systems. Meanwhile, in some countries without direct constitutional prohibitions of SES discrimination, individuals and civil society groups have used general guarantees of equal rights before the law for the same purposes, although not all courts have been receptive to this strategy. Second, constitutions continue to shape whether and how SES influences the exercise of civil and political rights, which has broader implications for whether laws and policies address the needs and interests of people at all income levels. For example, under various countries' constitutions, personal debt can jeopardize the ability to exercise political voice. Finally, constitutions can play a role in reducing income barriers to health and education. An overview of where the world stands in each area-and why these choices matter-follows.

\section{Addressing Discrimination with Explicit Protections}

Globally, 59\% of constitutions include explicit protections related to some aspect of SES, employing a diversity of terms for addressing SES discrimination (Map 24). For example, Bolivia's constitution provides that "[t] he State prohibits and punishes all forms of discrimination based on ... economic or social condition, type of occupation, [and] level of education." ${ }^{22}$ Malawi's constitution establishes that "[a]ll persons are, under any law, guaranteed equal and effective protection against discrimination on grounds of ... social origin ... property ... or other status or condition." ${ }_{33}$ 


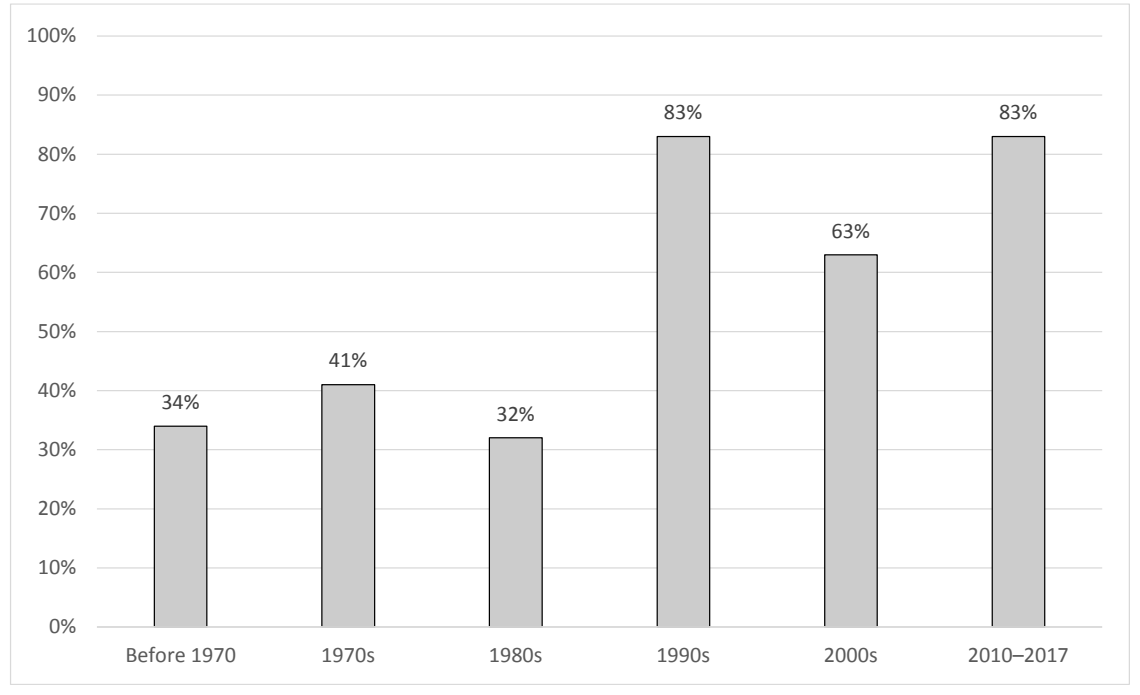

FIGURE 11. Explicit constitutional guarantee of equality or nondiscrimination across socioeconomic status by year of constitutional adoption

More recently adopted constitutions are likelier to explicitly prohibit SES discrimination: only about one-third of constitutions adopted before 1990 include an explicit guarantee, compared to more than three-quarters of those adopted since 1990 (see Figure 11). Still, the prevalence of these provisions falls far short of the share of constitutions that prohibit discrimination on the basis of race/ethnicity $(76 \%)$, gender $(85 \%)$, or religion $(78 \%)$.

\section{Nepal: Impact of Explicit Prohibitions of Caste Discrimination}

Since its founding in 1974, a Sanskrit education school in Kathmandu, Nepal, had admitted only students from the Brahmin caste, a hereditary distinction of high social class. Brahmins, who occupy the highest tier of the traditional Nepalese caste system, have historically received exclusive access to the highest-status jobs, such as priests and educators.

In 1990, however, Nepal's new constitution prohibited caste discrimination (though notably including an exception for "Hindu religious practices"). In 2009, Mohan Sashanker, a local lawyer, brought a public interest litigation challenge against the Kathmandu school, arguing that its admissions policy was discriminatory and unconstitutional. ${ }^{34}$ The Supreme Court agreed, finding that the policy violated the constitution's prohibitions on both untouchability and caste discrimination. In its ruling, the Court explained: "Education is to be acquired by human beings, not by a particular caste. The prestige of Sanskrit language does not diminish when acquired by persons of a particular caste and increase when pursued 
by persons of another caste ... [S] uch a distinction only promotes inequality in society."35

In recent years, Nepalese courts have struck down numerous laws and traditions that restricted members of the Dalit caste from accessing temples, public hostels, and schools on an equal basis with others. In September 2015, Nepal adopted a new constitution reaffirming the prohibition on caste discrimination. ${ }^{36}$ Although implementation of the law remains a critical challenge, ${ }^{37}$ these developments indicate a marked shift from the legalized discrimination that structured society just a few decades ago.

The Mohan Sashanker case clearly illustrates how a constitutional prohibition of caste discrimination can provide a legal tool for overturning explicit exclusionary practices. Addressing caste has important implications for SES.

\section{Belgium: Impact of Explicit Prohibitions on Class Discrimination}

Like Nepal, Belgium provides an example of a country where explicit protections mattered. Many countries, including Belgium, have long made a distinction in benefits guaranteed in legislation to people engaged in "blue collar" work, including manual labor, and "white collar" work, including office jobs, as well as between domestic service work and other forms of work. These distinctions may manifest in different sets of labor standards or benefits for each type of employment. Is there any legal justification for creating different classes of work, or is this differentiation just a cover for SES discrimination? Whether there is a legal justification may depend on the difference and its rationale. Constitutional guarantees against SES discrimination can help guarantee that these differences are not implemented for arbitrary reasons or based primarily on bias.

In Belgium, this question has worked its way through the courts and legislature for decades. While there are various differences between labor policies governing blue- and white-collar jobs in Belgium, one obvious example is sick leave. Whereas white-collar workers have historically been entitled to paid sick leave from the first day of illness, the first day for blue-collar workers was until recently designated as unpaid, unless their illness lasted for seven workdays or longer. In addition to ensuring workers do not have to sacrifice income to recover from illness or see doctors, providing sick leave from the first day of illness is important for preventing illnesses from spreading in workplaces. In Belgium, however, only white-collar workers have traditionally had access to this full coverage.

In 1993, Belgium's Constitutional Court held that the distinction between bluecollar and white-collar jobs in allocation of sick days and other benefits violated the constitution's equality provision, and ordered the legislature to gradually harmonize the policies that applied to both classes of workers. However, Parliament took no action for nearly 20 years. In July 2011, the Court once again pronounced the distinctions unconstitutional, this time focusing specifically on the disparities in sick leave and giving the legislature just two years to comply. ${ }^{38}$ Under Article 10 
of the Belgian Constitution, "[n]o class distinctions exist in the State," while Article 11 guarantees nondiscrimination in the enjoyment of rights and freedoms. ${ }^{39}$

Just before the deadline for complying with the 2013 order, Parliament passed a new act to comprehensively merge both systems. In addition to equalizing sick leave, the new law harmonized the rules on dismissals for both classes of workers. Prior to the law, blue-collar workers were entitled to 28-56 calendar days of notice, while white-collar workers were entitled to three months for every five years, or portion thereof, they had worked for the employer. $4^{40}$ Under the new regime, notice periods are determined strictly on the basis of seniority. With these changes, Belgium is on its way to becoming one of the final OECD countries to harmonize the labor laws applying to its two classes of workers. ${ }^{41}$

In Belgium and elsewhere, distinctions in benefits and labor protections between classes of workers are often premised on cost savings. Employers save money by withholding first-day sick leave benefits and providing shorter notice periods for terminations. Over time, these different standards for different types of jobs have become expected and normalized. However, as the Belgian Constitutional Court noted, this does not mean that the lesser protections provided to blue-collar workers were "based on objective and reasonable criteria." ${ }^{22}$ In other words, cost savings and tradition alone cannot justify discrimination under the constitution. This development provides an important example of how constitutions can provide a mechanism for increasing equality in labor conditions.

\section{Addressing Discrimination with General Equality Guarantees}

As in other areas of discrimination, broadly worded constitutional protections of overall equal rights have yielded inconsistent outcomes with regard to SES discrimination. In the absence of specific language, courts in some countries have been reluctant to recognize SES discrimination as unconstitutional. Finding SES similar to other grounds of discrimination the constitution clearly prohibits, courts in other countries have extended constitutional protection to SES. The United States and Canada provide examples of each possibility.

\section{United States: Poverty Receives Limited Protection}

Under the broadly worded Equal Protection Clause, race and religion have received the greatest protection - that is, the government must meet a higher standard to prove the necessity of any action that distinguishes among people based on these characteristics. Gender has been provided with intermediate protection. By contrast, discrimination on the basis of income, wealth, or social class receives only "rational basis," the lowest form of review. ${ }^{43}$

Under the rational basis standard, as illustrated in chapter 3, the person challenging the law must show either that the government has no legitimate purpose for the law, or that the law is not "rationally related" to that purpose. As Supreme 
Court Justice Potter Stewart explained in a 1980 opinion addressing the limited services covered by Medicaid, the federal healthcare program for very low-income adults, "this Court has held repeatedly that poverty, standing alone, is not a suspect classification." ${ }^{44}$ Consequently, as long as a given policy or practice is rationally connected to a legitimate government interest, it does not unconstitutionally discriminate on the basis of SES.

These low levels of constitutional protection make it hard to successfully oppose in court important forms of legal discrimination. For example, in most U.S. states, it remains legal to discriminate against prospective renters who plan to pay their rent using a federal housing subsidy ${ }^{45}$ — even as discrimination in housing on the basis of race, gender, religion, and other constitutionally protected statuses are all prohibited. ${ }^{46}$ As of 2018, 15 states had passed laws to prohibit "source of income" discrimination in housing, and studies suggest that these laws can increase the probability of finding housing by 12 percentage points. ${ }^{47}$ With such little protection against SES discrimination in federal law, however, low-income renters in most states commonly encounter property listings stating plainly they are ineligible to apply even when they receive adequate income and housing support to cover rent. ${ }^{48}$ In addition to the consequences for individuals, this exclusion may lead to further segregation across both SES and race/ethnicity in settings where historical discrimination and barriers have shaped SES disparities. ${ }^{49}$

\section{Canada: Poverty Is "Analogous" to Prohibited Bases of Discrimination}

By contrast, in 1993, a Canadian court deemed discrimination on the basis of poverty "analogous" to the prohibited grounds of discrimination enumerated in the Charter of Rights and Freedoms. Consequently, providing lower levels of legal protection to public housing renters compared to those living in private housing was found to be discriminatory and unconstitutional.

The appellant in the case was Irma Sparks, a 42-year-old black woman and single parent to two children. Sparks had moved into public housing in 1980 and had a year-to-year lease. ${ }^{\circ}$ On May 1, 1991, she received a notice to vacate within 30 days, in accordance with the requirements of her lease. However, the Residential Tenancies Act required landlords to give tenants in private housing at least three months' notice for a one-year lease. Additionally, the act provided that landlords could not serve a "notice to quit" on tenants who had lived in an apartment for five years or longer, unless they stopped paying rent. Facing eviction and likely homelessness, Sparks brought a lawsuit challenging the lower levels of protections provided to public housing tenants, and contesting her own notice to vacate as discriminatory on the bases of race, sex, marital status, and poverty.

At trial, the judge dismissed Sparks's complaint, holding that the differential treatment of public housing residents did not single out women, black people, or single mothers. ${ }^{51}$ However, the Nova Scotia Court of Appeal found that the 
challenged provision amounted to "adverse effect discrimination," similar to "disparate impact" discrimination in other jurisdictions, on all four grounds Sparks had argued. As a result, the Court struck down the portions of the Residential Tenancies Act that excluded public housing tenants from the fundamental protections that other renters enjoyed, newly extending these basic safeguards to approximately 10,000 tenants across the province. ${ }^{52}$

Other countries have also overturned SES discrimination based on the association of SES and race/ethnicity. The United Kingdom's first legal case of caste discrimination was decided on the basis of protections against race discrimination in the country's Equality Act, ${ }^{53}$ prompting the government to begin a consultation on whether "caste" should be specifically protected too..$^{54}$

As these contrasting examples from the U.S. and Canada show, general equality provisions may provide some protection against SES discrimination, but we cannot presume these broadly worded guarantees will be sufficient. According to analysts from the International Network for Economic, Social and Cultural Rights, the finding in the Irma Sparks case "that poverty is a prohibited ground of discrimination was ground-breaking," signaling that such a result is uncommon when SES is not explicitly listed as a prohibited ground of discrimination..$^{55}$

\section{Political Rights and Representation}

Ensuring that democracies are accountable to people across the socioeconomic spectrum is fundamental to equality. A foundation of equal political rights is one part of the solution. Joining a union, voting, and running for political office are all important ways that citizens can express their political voice, and these rights and opportunities must be guaranteed to all regardless of income, wealth, property, or occupation. Historically, as mentioned earlier and in prior chapters, governments have employed policies like poll taxes, literacy tests, and property or tax requirements to disenfranchise would-be voters, disproportionately affecting citizens with lower SES in ways that intersect with other forms of marginalization.

These barriers continue. ${ }^{56} \mathrm{~A}$ quarter of countries constitutionally restrict the right to hold office based on SES. Although such restrictions have become less common, SES-based limitations on political rights were still included in $13 \%$ of the constitutions enacted between 2010 and 2017 (see Figure 12).

The majority of these restrictions are based on personal debt, with prohibitions on legislators having bankruptcies, insolvency, or creditor debt. Antigua and Barbuda's constitution states: "No person shall be qualified to be elected as a member of the House who: . . . is an undischarged bankrupt, having been declared bankrupt under any law."57 Other constitutions go beyond debt. Haiti establishes that any candidate to the lower house of the legislature must "be the owner of real assets in the circumscription or exercise a profession or an industry there." ${ }^{38}$ Denmark's constitution provides that "[i]t shall be laid down by Statute to what extent conviction and public assistance amounting to poor relief within the meaning of 


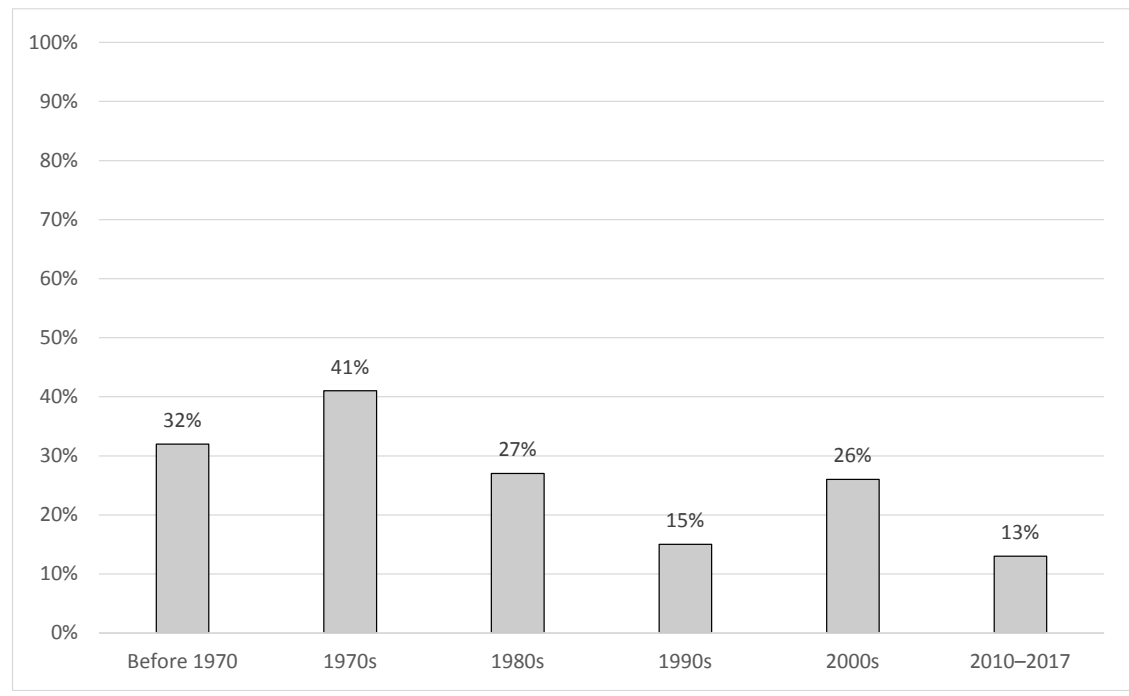

FIGURE 12. Explicit constitutional limits on holding office based on income by year of constitutional adoption

the law shall entail disfranchisement," and stipulates that only those who have the right to vote can hold office. ${ }^{59}$

Most agree that prohibiting citizens from voting based on their use of public assistance or other SES indicators is discrimination. However, some argue that restrictions on debtors serving as public officials are necessary to prevent corruption and susceptibility to bribes. While supported by some anecdotal evidence, ${ }^{60}$ this theory is largely speculative; researchers who study corruption's causes caution that " $\mathrm{i}] \mathrm{t}$ is difficult to know when, or if what factors are responsible for acts of fraud and corruption, as they are multi-layered and complex." ${ }^{61}$ Moreover, the level of documented corruption among wealthy public officials across countries suggests that this justification is merely pretext for SES discrimination. ${ }^{62}$

The practical impacts of limiting rights on the basis of debt can also be severe. In Moldova, the Constitutional Court recently struck down a ban on issuing marriage licenses, divorce papers, driver's licenses, and passports to individuals with debt, pronouncing the ban an unconstitutional infringement of the rights to privacy and freedom of movement. In particular, the Court found that the constitution required a balancing of interests, and that an interminable ban on fundamental documents was disproportionate to the goal of enforcing a creditor's rights. ${ }^{63}$

\section{Education and Health and Their Foundational Role in Realizing Broader Rights}

Finally, constitutional rights can provide tools for removing barriers linked to SES in key areas that are foundational to health, education, and opportunity. In 
addition to providing overall rights to health and education, for example, constitutions can guarantee that schools and healthcare will be free, or at least that cost will not be a barrier to access for those who cannot afford to pay. Cases from Colombia and Kenya illustrate these approaches in action.

\section{Colombia: Accounting for Costs in School Assignments}

In Mora v. Bogota District Education Secretary \& Ors, ${ }^{64}$ a five-year-old girl was assigned to a school outside her district by local education authorities, who divided students among schools based on capacity. Consequently, her family would have to pay for transportation to the school, which created an insurmountable cost burden.

The girl's mother challenged her daughter's assignment to the school as a violation of her constitutional right to education. Colombia's constitution guarantees that public education is free, and further states that "[i]t is the responsibility of the State to ... guarantee for minors the conditions necessary for their access to and retention in the educational system." ${ }^{65}$ In 2003, Colombia's Constitutional Court agreed, finding that the school district should "take into account social and economic factors" in assigning students to schools, and that the right to education and the safety of the child should prevail over other considerations. ${ }^{66}$ As a result, the Court ordered the girl's admittance to one of the three schools within her neighborhood.

\section{Kenya: Addressing Accessibility of Health Services Regardless of SES}

The fundamental principle underlying the Mora $v$. Bogota decision is that SES should not be a barrier to fundamental public goods and services like education. The same is true for health, as illustrated by a case decided nine years later in Kenya. ${ }^{67}$

The petitioners, Millicent Awuor Omuya and Margaret Anyoso Oliele, were mothers who had just given birth but were detained at the hospital in unsafe and unsanitary conditions because they could not pay their medical bills in full. Omuya had initially gone to give birth at a clinic where she knew she could afford the fee, but when it appeared that her baby was in breech position, she was referred to Pumwani Maternity Hospital, where her costs more than tripled. As it turns out, Omuya gave birth without complications just 15 minutes after arriving at the hospital, but she was still charged the full fee. When she could not pay it, she was detained for 24 days. Oliele, meanwhile, was a 15-year-old girl who delivered by caesarean section and then lost consciousness for 10 days. When she woke, she was detained for another seven days for her inability to pay. ${ }^{68}$ Both patients, who had other children to care for at home, were released only when their friends and family helped pay their outstanding bills. ${ }^{69}$

The Kenyan High Court found that the hospital's actions violated the women's rights to liberty, freedom of movement, dignity, and health, and that they had been 
unconstitutionally discriminated against "on the basis of their economic status."7o Article 43 of the Kenyan Constitution provides that "everyone has . . . the right to health care services, including reproductive health care," while Article 27 prohibits direct and indirect discrimination on "any ground," including "social origin." Additionally, Article 21(3) establishes that the state has "the duty to address the needs of vulnerable groups within society," which the Court held to clearly include "poor expectant women who are in labour." ${ }^{71}$ In summary, the Court held: "The result is that there was a disproportionate impact on poor women's ability to access health care, which constitutes discrimination on the basis of social origin, and negates the right of women to enjoy their constitutionally guaranteed rights and freedoms. The consequences of this pervasive discrimination is the inaccessibility of maternal health services overall, which in turn hinders the attainment of the highest attainable standard of health for poor women." ${ }^{2}$

As a remedy, the Court ordered the Nairobi county government, which funded the hospital, to pay substantial damages to the two women; ordered the eradication of the practice of detaining patients who could not pay their bills; and called on the government for stronger implementation of policies providing for fee waivers in public hospitals for patients in need.

\section{Current Constitutional Approaches}

As these cases from Colombia and Kenya show, across both education and health, upholding the fundamental principle of equal access regardless of SES may require governments to remove cost barriers through affirmative steps rather than merely prohibiting discrimination. Currently, over half of constitutions guarantee free primary education, although only one-third extend this same guarantee to secondary school. Only 10\% guarantee universally free medical care, although an additional $6 \%$ guarantee the right to medical services specifically for low-income adults and children. Through these guarantees, constitutions can play a critical role in reducing disadvantage linked to SES and supporting universal access to two fundamental building blocks of opportunity and well-being.

\section{IMPLEMENTATION CHALLENGES}

\section{AND CONSIDERATIONS}

SES plays an important role in access not only to public and private sector opportunities, decent working conditions, and basic health and educational services, but also to justice. Lack of resources to hire a lawyer and initiate a lawsuit often makes the enforcement of rights through the courts a practical impossibility for people in poverty. Although these challenges affect all people's ability to claim their rights, they have a disproportionate impact on the basis of SES. However, there is significant variation in the extent to which countries' constitutions and legal systems 
support equal justice for all. Assessing which strategies are effective and which are likely to further marginalize people in poverty is important for evaluating whether the other rights examined in this chapter will have impact.

\section{Cases Brought by and on Behalf of Groups}

Access to the courts is directly shaped by countries' rules on legal standing, which determine who is eligible to bring a claim and under what circumstances. Under most countries' rules, individuals cannot bring claims before the courts unless they have been personally affected, and the right to individually apply to the Supreme or Constitutional Court may be subject to further restrictions. However, many countries allow plaintiffs to bring claims on behalf of a class. Some, such as India, do not require plaintiffs to have been directly affected by the issue at hand if there is evidence that it has had a broad societal impact.

Being able to bring a claim on behalf of a group presents many advantages. First, from an administrative standpoint, courts can achieve greater efficiency when they can address multiple similar claims at once rather than a series of individual claims. Given that many countries' courts systems are overburdened, this is an important consideration for supporting access to justice more broadly. Second, collective claims can ensure that the benefits of litigation reach a much broader population, including those likely lacking the resources to hire a lawyer on their own. Finally, collective claims can expose major gaps or flaws in laws and policies and catalyze structural reforms.

Collective legal actions take different forms in different countries and go by varying names. Across regions, group-based approaches to enforcing fundamental rights have provided a tool for compelling action for large populations, rather than for single individuals. In India and Nepal, "public interest litigation" has become a powerful mechanism for advancing human rights and demanding greater government accountability. In Delhi, for example, a public interest litigation case on poor air quality resulted in new regulations on commercial vehicles, which the World Bank estimated saved over 14,00o lives between 2002 and 2006.73 In other countries, like the United States, class action lawsuits or so-called "impact litigation" can have similar aims and effects, although they still require a plaintiff or plaintiffs who have been personally harmed. For example, class actions have been used in the U.S. to secure justice for a community whose water was contaminated by a utility company, ${ }^{74}$ enforce protections against sexual harassment for female mine workers, ${ }^{75}$ and uphold the right to family visits for prisoners. ${ }^{76}$ More recently, the former Soviet states of Central and Eastern Europe have embraced variants of public interest litigation, which have been effectively used to challenge discrimination in public services, education, and employment. ${ }^{77}$

\section{Access to Legal Representation and Assistance}

The assistance of an attorney is often critical for claiming rights, effectively navigating the legal system, and accessing a fair process. However, many low-income 
people cannot afford a lawyer and are not provided one by the state, or are guaranteed legal counsel only in limited circumstances. While class actions can help democratize the benefits of legal representation, access to lawyers is a separate approach to improve the realization of rights across SES. This is important especially for legal issues that are individual by nature.

Around the world, the importance of guaranteeing the right to counsel at key stages of the criminal process is getting closer to global consensus. ${ }^{78}$ In 2013, the European Union (EU) enacted a Directive on Access to a Lawyer, which is binding on all EU states and requires that "suspects or accused persons have the right of access to a lawyer without undue delay." 79 Meanwhile, according to a 2016 study of 125 countries' legal frameworks by the United Nations Development Program, the majority take some approach to guaranteeing the right to counsel in criminal cases through their constitutions; a small but growing number make clear, primarily through legislation, that free access to a lawyer extends to indigent civil litigants. ${ }^{80}$ To ensure access to justice regardless of SES, this will be an important area for further global reform.

\section{Social Rights vs. Social Policies?}

Because of the above challenges, some have claimed that putting too much emphasis on a rights-based framework may take the pressure off governments to enact strong social policies that affirmatively provide for the needs of the poor, rather than fulfilling basic needs only upon demand. Likewise, some have argued that social and economic rights in particular disproportionately benefit the rich, who have easier access to courts. However, there is little evidence that governments are making calculated trade-offs between strong constitutional rights and strong social policies; in fact, research has demonstrated that at least in the context of education, the existence of a constitutional right is positively associated with the existence of a national policy ${ }^{81}$ Additionally, neither of these approaches to change acts in isolation. Class actions in particular can lead to the strengthening and expansion of social policies, with benefits for large populations. For example, the "right to food" case in India, which expanded the country's free school lunch program, improved nutrition for nearly 10 million children and boosted girls' firstgrade enrollment by $10 \%$ per year. $^{82}$

Further, recent empirical research has shown that economic and social rights litigation can have benefits that disproportionately affect lower-income communities and extend far beyond the parties in the case, depending on the nature of the claim. ${ }^{83}$ For example, in South Africa, a case holding that asylum seekers could not be excluded from receiving public education or seeking work is estimated to have impacted over 50,000 individuals, all of whom were socioeconomically disadvantaged. ${ }^{84}$ Similarly, in India, litigation to reduce air pollution in Delhi improved health for hundreds of thousands, and disproportionately benefitted people in the two lowest income quintiles, which include $47 \%$ of those diagnosed with asthma. ${ }^{85}$ 
Although improving access to the courts and legal aid is critical for ensuring countries' judicial systems are effective for people across SES, the litigation process itself is not inherently at odds with "pro-poor" aims - and, in fact, can be a powerful tool to support these movements.

\section{Participatory Drafting Processes}

Participatory drafting has shown potential for designing constitutions that more comprehensively address the needs and interests of marginalized communities. According to one longitudinal study of 138 constitutions, countries whose constitutions were drafted with more direct citizen participation had higher levels of democratic practices after the constitutions' enactment. ${ }^{86}$ Increasing the involvement of people across SES in the constitutional drafting process can strengthen the extent to which constitutions effectively protect rights regardless of SES.

Examples from individual countries illustrate the feasibility of widespread participation. In South Africa, for example, the government undertook a comprehensive process of education and public consultation while drafting its 1996 constitution, which prioritized the input of marginalized communities. The education component, which focused on building general knowledge about the constitution and citizens' right to submit input, reached over 95,00o rural and marginalized people through over 1,00o participatory workshops, while its media campaign reached $73 \%$ of adult South Africans through radio broadcasts in eight languages. ${ }^{87}$ As part of the consultation component, members of the Constituent Assembly met with 20,500 individuals and 717 organizations over the course of 27 public meetings, all of which took place in rural and disadvantaged areas. ${ }^{88}$ Finally, after a draft of the constitution was prepared, the public had another opportunity to submit comments before the final negotiation. ${ }^{89}$

Establishing a responsive, accountable, and inclusive relationship between the government and the people is a key function of constitutions. Creating inclusive and equitable processes for drafting these fundamental documents is a first step toward ensuring that constitutions lay the foundation for more inclusive and equitable laws, policies, and practices.

SES discrimination is often overlooked in constitutions, even as it profoundly shapes health, educational and economic opportunities, and the ability to exercise other fundamental rights. Including more people who have felt the impacts of this type of discrimination firsthand in the process of building constitutions, while deepening our collective understanding of how constitutional protections on the basis of SES have made a difference in people's lives globally, can help ensure constitutions fulfill their potential as powerful instruments of democracy.

\section{CONCLUSION}

Beginning with the UDHR, countries around the world agreed that fundamental rights and freedoms should not be contingent on "social origin, property, birth or 
other status." ${ }^{\circ}$ Likewise, the UDHR and key international treaties adopted during the following decades, including the ICCPR and the ICESCR, embraced a multidimensional approach to poverty alleviation that recognizes the importance of access to education, healthcare, fair labor conditions, and political rights and participation. In 1995, through the Copenhagen Declaration on Social Development, 118 world leaders committed their countries to "create an enabling economic environment aimed at promoting more equitable access for all to income, resources and social services" and to reaffirm and strive to realize the rights embodied in international treaties, "including those relating to education, food, shelter, employment, health and information, particularly in order to assist people living in poverty." ${ }^{91}$ And in 2015, all 193 U.N. member states unanimously committed to ending poverty and reducing inequality by adopting the SDGs.

In theory, then, there is wide global agreement on preventing SES discrimination and ensuring that having a low income does not preclude full participation in society. But in practice, we still have far to go-and addressing the gap between these international commitments and countries' domestic legal frameworks is an important first step. Globally, nearly half the world's constitutions fail to prohibit discrimination on any aspect of SES. Even fewer guarantee that the ability to pay will not be an insurmountable obstacle to accessing healthcare and an adequate education. While some forms of SES discrimination may not be immediately apparent, a greater political commitment to identifying and testing for these more invidious forms of bias would go a long way toward realizing equal rights for all. In the context of rising economic inequality globally, strengthening protections on the basis of SES has become all the more critical. 